\title{
Global glacier changes: a revised assessment of committed mass losses and sampling uncertainties
}

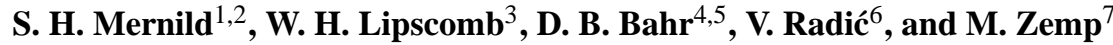 \\ ${ }^{1}$ Climate, Ocean and Sea Ice Modeling Group, Computational Physics and Methods, Los Alamos National Laboratory, Los \\ Alamos, NM 87545, USA \\ ${ }^{2}$ Glaciology and Climate Change Laboratory, Center for Scientific Studies/Centro de Estudios Cientificos (CECs), Chile \\ ${ }^{3}$ Climate, Ocean and Sea Ice Modeling Group, Fluid Dynamics and Solid Mechanics, Los Alamos National Laboratory, Los \\ Alamos, NM 87545, USA \\ ${ }^{4}$ Institute of Arctic and Alpine Research, University of Colorado, Boulder, CO 80309, USA \\ ${ }^{5}$ Institut für Geographie, Universität Innsbruck, Innrain 52, 6020 Innsbruck, Austria \\ ${ }^{6}$ Department of Earth and Ocean Sciences, University of British Columbia, Vancouver, Canada \\ ${ }^{7}$ Department of Geography, University of Zurich, Zurich, Switzerland
}

Correspondence to: S. H. Mernild (mernild@cecs.cl)

Received: 9 April 2013 - Published in The Cryosphere Discuss.: 7 May 2013

Revised: 12 August 2013 - Accepted: 20 August 2013 - Published: 2 October 2013

\begin{abstract}
Most glaciers and ice caps (GIC) are out of balance with the current climate. To return to equilibrium, GIC must thin and retreat, losing additional mass and raising sea level. Because glacier observations are sparse and geographically biased, there is an undersampling problem common to all global assessments. Here, we further develop an assessment approach based on accumulation-area ratios (AAR) to estimate committed mass losses and analyze the undersampling problem. We compiled all available AAR observations for 144 GIC from 1971 to 2010, and found that most glaciers and ice caps are farther from balance than previously believed. Accounting for regional and global undersampling errors, our model suggests that GIC are committed to additional losses of $32 \pm 12 \%$ of their area and $38 \pm 16 \%$ of their volume if the future climate resembles the climate of the past decade. These losses imply global mean sealevel rise of $163 \pm 69 \mathrm{~mm}$, assuming total glacier volume of $430 \mathrm{~mm}$ sea-level equivalent. To reduce the large uncertainties in these projections, more long-term glacier measurements are needed in poorly sampled regions.
\end{abstract}

\section{Introduction}

Averaged over a typical year, glaciers accumulate snow at upper elevations and ablate snow and ice at lower elevations. When the total accumulation is equal, on average, to the total ablation, a glacier is in balance with its local climate. If accumulation exceeds ablation over a period of years to decades, glaciers must thicken and advance; if ablation exceeds accumulation, glaciers must thin and retreat. Most of the Earth's glaciers are retreating (e.g., Meier et al., 2007; Bahr et al., 2009; WGMS, 2012).

Glacier annual mass balance has been measured by direct field methods for about 340 glaciers and ice caps (GIC), of which about 70 have uninterrupted records of 20 years or more (Dyurgerov, 2010; WGMS, 2012). This is a very small fraction of the Earth's estimated 200000 or more GIC (Arendt et al., 2012). Globally integrated GIC mass changes cannot be measured directly, but must be estimated by upscaling observations from a small number of glaciers and ice caps. Several analyses (Dyurgerov and Meier, 2005; Kaser et al., 2006; Meier et al., 2007; Cogley, 2009a, 2012) based on direct and geodetic measurements suggest that GIC mass loss is currently raising global mean sea level by about $1 \mathrm{~mm} \mathrm{yr}^{-1}$. This is about one-third of the total rate of sealevel rise inferred from satellite altimetry, with ocean thermal 
expansion and ice-sheet mass loss accounting for most of the remainder (Cazenave and Llovel, 2010). GRACE gravity measurements from 2003 to 2010 suggest a smaller GIC sea-level contribution of about $0.4 \mathrm{~mm} \mathrm{yr}^{-1}$, excluding GIC peripheral to the Greenland and Antarctic ice sheets (Jacob et al., 2012). These GRACE estimates, however, have large regional uncertainties and rely on the performance of global hydrologic models. Gardner et al. (2013) recently combined satellite gravimetry and altimetry with local glaciological measurements to estimate that the Earth's GIC raised sea level by $0.71 \pm 0.08 \mathrm{~mm} \mathrm{yr}^{-1}$ during the period 2003-2009.

Several modeling studies have projected global-scale transient glacier mass changes in response to forcing from climate models (e.g., Raper and Braithwaite, 2006; Radić and Hock, 2011; Marzeion et al., 2012; Slangen et al., 2012). Based on output from 10 global climate models prepared for the Fourth Assessment Report of the Intergovernmental Panel on Climate Change (IPCC AR4), sea level is projected to rise by $124 \pm 37 \mathrm{~mm}$ during the 21 st century from GIC mass loss, with the largest contributions from Arctic Canada, Alaska, and Antarctica (Radić and Hock, 2011). Another study (Marzeion et al., 2012) used 15 global climate models prepared for the IPCC Fifth Assessment Report (AR5) to project that GIC mass loss by 2100 will range from $148 \pm 35 \mathrm{~mm}$ to $217 \pm 47 \mathrm{~mm}$, depending on the emission scenario. For model calibration and validation, these studies used direct and geodetic mass balance observations available for much fewer than $1 \%$ of the Earth's glaciers. Undersampling is a significant problem for these studies and for all methods that project global sea-level rise from GIC.

Bahr et al. (2009, henceforth BDM) developed an alternative approach for projecting global glacier volume changes. This approach is based on the accumulation-area ratio (AAR), the fractional glacier area where accumulation exceeds ablation. For a glacier in balance with the climate, the AAR is equal to its equilibrium value, $\mathrm{AAR}_{0}$. Glaciers with $\mathrm{AAR}<\mathrm{AAR}_{0}$ will retreat from lower elevations, typically over several decades or longer, until the AAR returns to the equilibrium value. In the extreme case $\mathrm{AAR}=0$, there is no accumulation zone and the glacier must disappear completely (Pelto, 2010). From the ratio $\alpha=\mathrm{AAR} / \mathrm{AAR}_{0}$, $\mathrm{BDM}$ derived $p_{A}$ and $p_{V}$, the fractional changes in area $A$ and volume $V$ required to reach equilibrium with a given climate. They showed that for a given glacier or ice cap, $p_{A}=\alpha-1$ and $p_{V}=\alpha^{\gamma}-1$, where $\gamma$ is the exponent in the glacier volume-area scaling relationship, $V \propto A^{\gamma}$ (Bahr et al., 1997). Data and theory suggest $\gamma=1.25$ for ice caps and $\gamma=1.375$ for glaciers. Using AAR observations of $\sim 80$ GIC during the period 1997-2006 (Dyurgerov et al., 2009), BDM computed a mean AAR of $44 \pm 2 \%$, with $\mathrm{AAR}<\mathrm{AAR}_{0}$ for most GIC. They estimated that even without additional warming, the volume of glaciers must shrink by $27 \pm 5 \%$, and that of ice caps by $26 \pm 8 \%$, to return to equilibrium.
The AAR method provides physics-based estimates of committed GIC area and volume changes, and complements techniques such as mass balance extrapolation (Meier et al., 2007) and numerical modeling (Oerlemans et al., 1998; Raper and Braithwaite, 2006). Compared to direct mass balance measurements, AARs are relatively easy and inexpensive to estimate with well-timed aerial and satellite images, which could potentially solve the undersampling problem. Here we adopt the BDM approach and develop it further. Instead of assuming that a sample of fewer than 100 observed GIC, mostly in Europe and western North America, is representative for the global mean, we test the foundations of this assumption and quantify its uncertainties. We aim not only to provide a revised estimate of committed global-scale glacier mass losses but also to assess the sampling errors associated with the limited number of available AAR observations.

\section{Data and methods}

We compiled a data set of AAR (\%) and mass balance $\left(\mathrm{kg} \mathrm{m}^{-2} \mathrm{yr}^{-1}\right)$ for 144 GIC (125 glaciers and 19 ice caps) from 1971 to 2010, mainly from the World Glacier Monitoring Service (WGMS, 2012) but with additional data from Dyurgerov and Meier (2005), Bahr et al. (2009), and individual investigators. (See Sheet A in the supplementary material.) Thus we expanded and updated the data set used by BDM. We found that the BDM data set generally omits AARs for glaciers with net ablation at all elevations (hence $A A R=0$ ) in a particular year. Including these values lowers the mean AAR. Figure 1 shows the locations of GIC in the updated data set, and Fig. 2 shows the number of GIC with AAR observations in each year.

These data were distilled from a larger data set that included several dozen additional glaciers in the WGMS database. For each glacier or ice cap we computed $\mathrm{AAR}_{0}$ by linear regression of the AAR with mass balance (Fig. 3 and Sheet B of the supplementary material). We retained only those GIC for which the linear relationship is statistically significant ( $p<0.10$, based on a linear regression $t$ test) in order to remove GIC with short time series and those for which AAR methods are not applicable. Instances of $A A R=0$ and $\mathrm{AAR}=100 \%$ were excluded from the regressions (but included for the broader analysis), since AAR and mass balance are not related linearly when net ablation occurs at all elevations or when net accumulation occurs at all elevations. Following Dyurgerov et al. (2009), we assumed that $\mathrm{AAR}_{0}$ does not change in time.

We then computed annual, pentadal, and decadal averages of AAR and $\alpha$ for selected regions (Fig. 1) and for the full data set, along with the fractional change in area $p_{A}$ and volume $p_{V}$ required for GIC to reach equilibrium with a given climate (see Appendices A and B for details). The arithmetic mean AAR and $\alpha$ have fallen during each decade since the 1970s (Fig. 4). We found a decadal-average $\alpha<1$, implying 


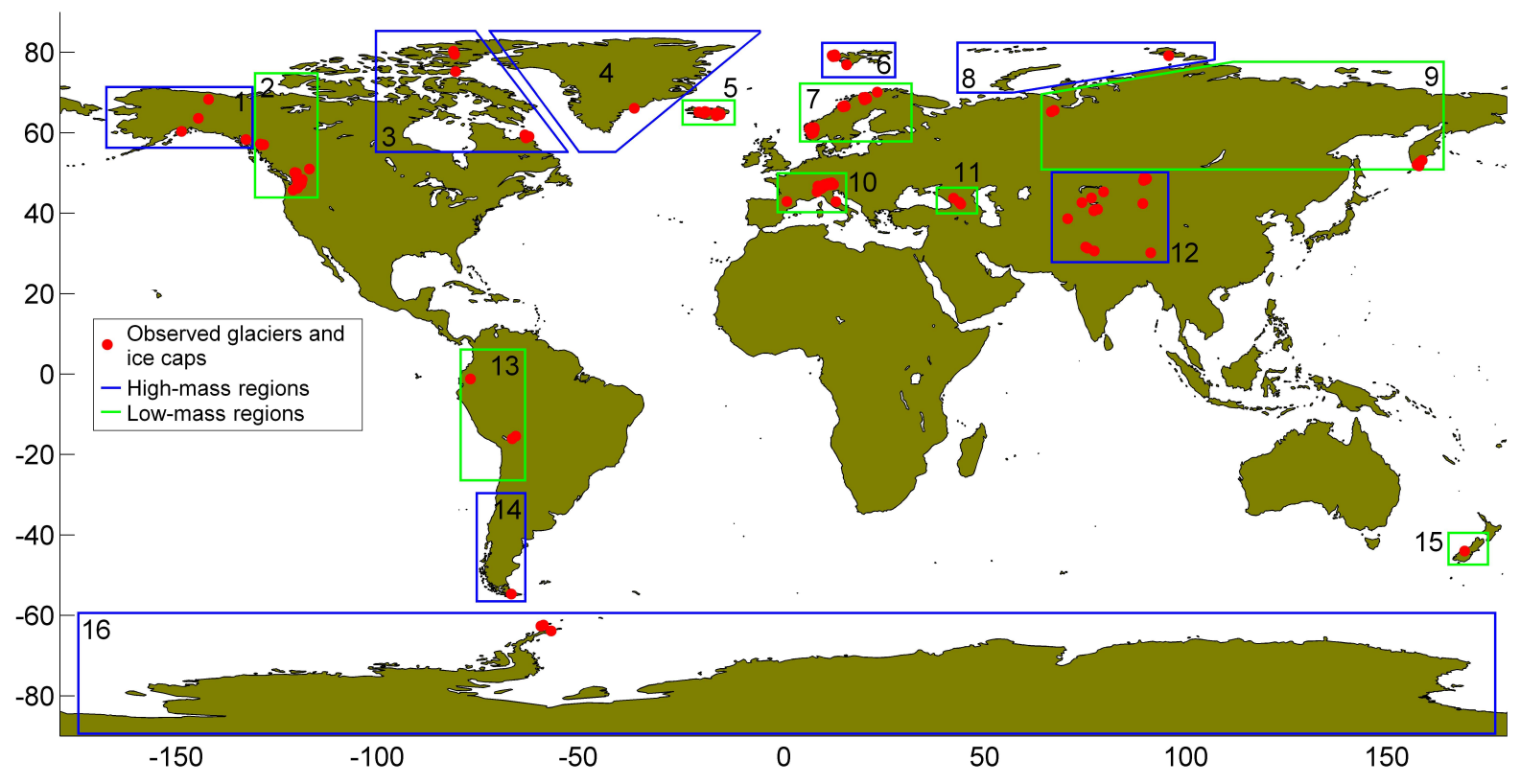

Fig. 1. Locations of the 144 glaciers and ice caps (GIC) in the updated data set. The data are divided into 16 regions: (1) Alaska, (2) western Canada/US, (3) Arctic Canada, (4) Greenland, (5) Iceland, (6) Svalbard, (7) Scandinavia, (8) the Russian Arctic, (9) North Asia, (10) central Europe, (11) the Caucasus, (12) central Asia, (13) the northern Andes, (14) the southern Andes, (15) New Zealand, and (16) Antarctica. The data set contains 38 GIC in high-mass regions (ice volume $V>5000 \mathrm{~km}^{3}$, outlined in blue) and $106 \mathrm{GIC}$ in low-mass regions $\left(V<5000 \mathrm{~km}{ }^{3}\right.$, outlined in green). Volume estimates are from Radić et al. (2013).

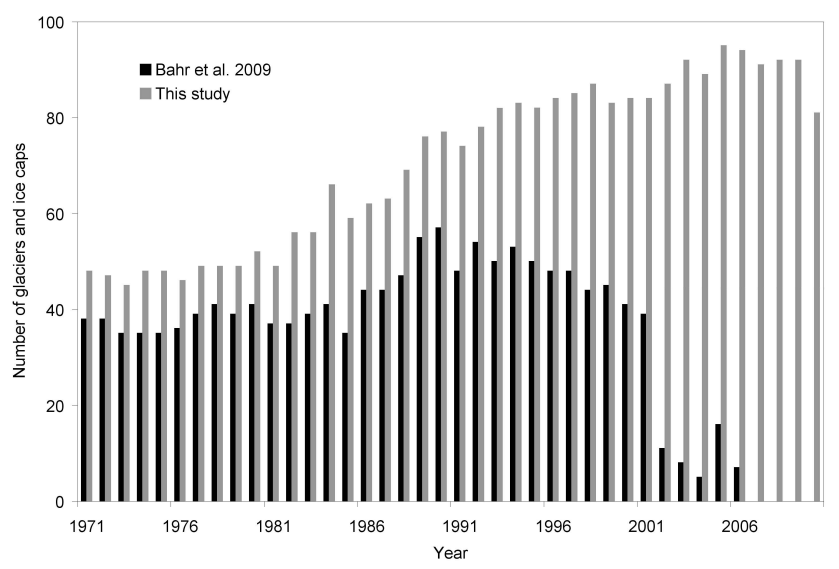

Fig. 2. Number of glaciers and ice caps with AAR observations per year in the Bahr et al. (2009) data set (black) and in the updated data set used in this study (grey).

future retreat if recent climate conditions continue, for 93 out of 96 GIC with observations during the 2000s. The mean AAR for 2001-2010 is $34 \pm 3 \%$. This is well below BDM's estimate of $44 \pm 2 \%$, indicating that the observed GIC are farther from balance than previously reported. (Here and below, error ranges computed from our data set correspond to a $95 \%$ confidence interval, or 1.96 times the standard error. Uncertainty ranges in other published work may not be directly comparable. BDM, for example, expressed uncertain-

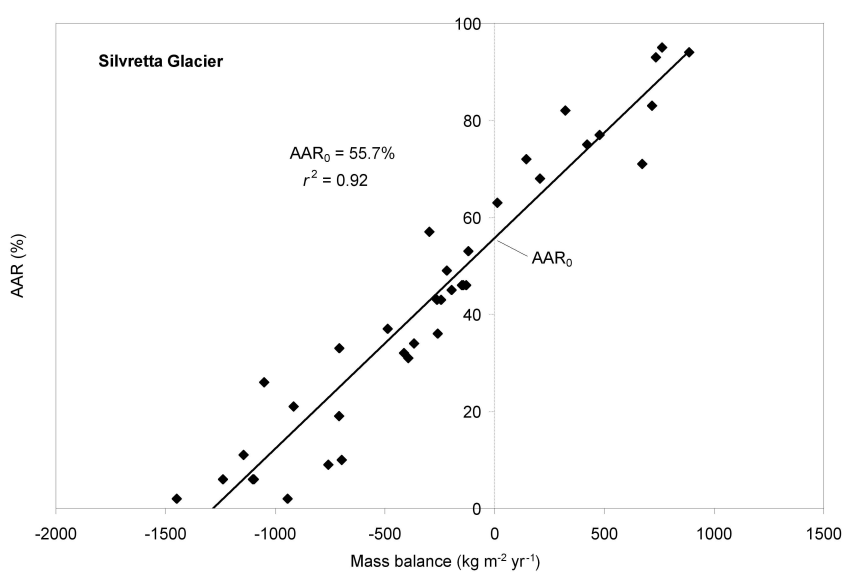

Fig. 3. Linear regression of AAR against mass balance for Silvretta Glacier, Swiss Alps. The $y$ intercept is $\mathrm{AAR}_{0}$, the equilibrium value of AAR. Each diamond represents one year of data.

ties as plus or minus one standard error, corresponding to a $68 \%$ confidence interval.)

GIC observations are sparse and geographically biased, thus complicating any extrapolation of global glacier mass loss from the available data. Direct AAR and mass-balance measurements have focused on small to mid-sized glaciers in accessible regions such as the Alps, Scandinavia, and the western US and Canada (Fig. 1). Based on Radić et al. (2013), we divided the Earth's glaciated regions into eight 


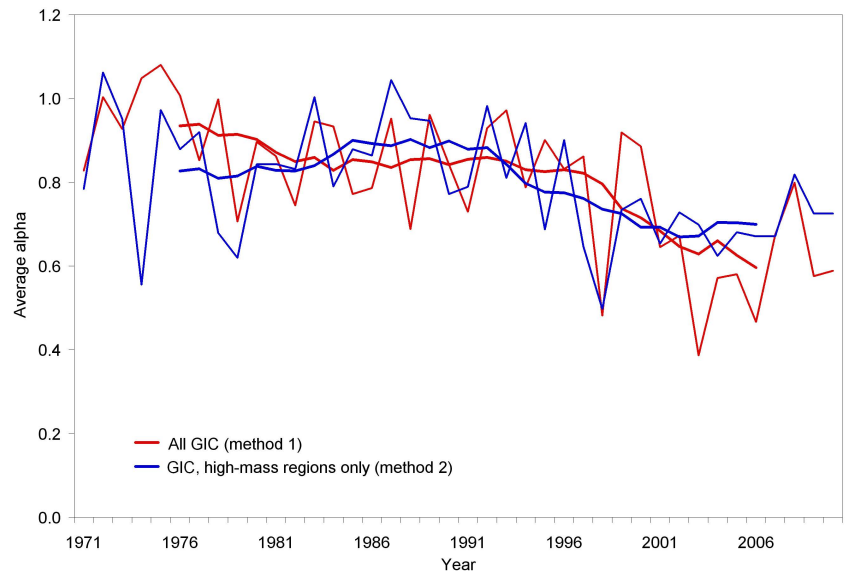

Fig. 4. Annual average $\alpha=\mathrm{AAR} / \mathrm{AAR}_{0}$ for the full data set (thin red line) and for the GIC in high-mass regions only (thin blue line), 1971-2010. The thick red and blue lines are $10 \mathrm{yr}$ running means. Both the full data set and the high-mass-only data sets have significant $(p<0.01)$ negative trends during the periods 1971-2010 and 1991-2010. The 1971-1990 trends are not significant $(p>0.10)$.

high-mass regions (each with an ice volume $V>5000 \mathrm{~km}^{3}$ ) and eight low-mass regions $\left(V<5000 \mathrm{~km}^{3}\right)$. The data set includes 38 GIC in high-mass regions (Arctic Canada, Antarctica, Alaska, Greenland, the Russian Arctic, central Asia, Svalbard, and the southern Andes) and 106 GIC in low-mass regions (Iceland, western Canada/US, the northern Andes, central Europe, Scandinavia, North Asia, the Caucasus, and New Zealand). The high-mass regions collectively contain about $97 \%$ of the Earth's glacier mass.

Area is not correlated significantly $(p>0.10)$ with AAR or $\alpha$ for observed GIC spanning a range of $\sim 0.1$ to $1000 \mathrm{~km}^{2}$ (Fig. 5), suggesting that glacier size is not a large source of bias. Geographic bias, on the other hand, could be important. In our data set, only 23 of 96 GIC with observed AAR during the period 2001-2010 are in high-mass regions. Table 1 shows the decadal mean $\alpha$ for each of 14 regions with one or more GIC in the 2001-2010 data set. Among regions with at least three observed GIC, the highest values are in Alaska $(\alpha=0.89 \pm 0.28)$ and Antarctica $(\alpha=0.89 \pm 0.28)$, with the lowest values in Svalbard $(\alpha=0.49 \pm 0.15)$ and central Europe $(\alpha=0.47 \pm 0.06)$. Three regions with low glacier mass (central Europe, Scandinavia, and western Canada/US) contain more than half the GIC in the data set and have relatively low $\alpha$. These regional differences suggest that the full data set may not be spatially representative and that projections based on the arithmetic mean $\alpha$ could overestimate committed GIC losses.

To show how geographical bias and undersampling can affect estimates of global glacier mass balance and AAR, we applied three different averaging methods: (1) the arithmetic mean for the full data set; (2) the arithmetic mean for the GIC in high-mass regions only; and (3) a mean obtained by up-

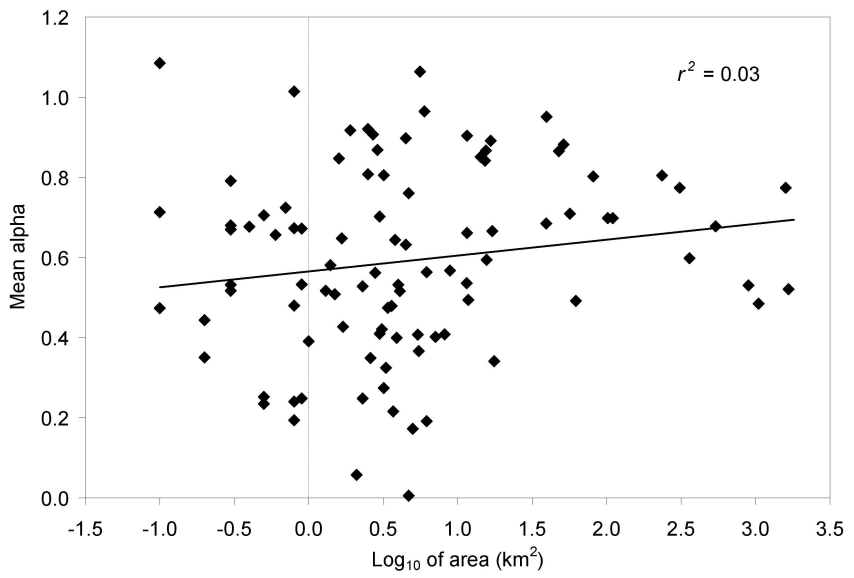

Fig. 5. Linear relation between the log of area $\left(\mathrm{km}^{2}\right)$ and the 20012010 mean $\alpha=\mathrm{AAR} / \mathrm{AAR}_{0}$ for 96 GIC with observations in the past decade. Each diamond represents one glacier or ice cap. The correlation between $\alpha$ and the log of area, although slightly positive $\left(r^{2}=0.03\right)$, is insignificant $(p>0.10)$, suggesting that a bias toward smaller glaciers does not imply a bias in $\alpha$.

Table 1. Regional mean values of $\alpha=\mathrm{AAR} / \mathrm{AAR}_{0}$ for 2001$2010^{*}$.

\begin{tabular}{lc}
\hline Region & Mean $\alpha$ \\
\hline Alaska (3) & $0.89 \pm 0.28$ \\
W. Canada/US (19) & $0.57 \pm 0.06$ \\
Arctic Canada (2) & $0.60 \pm 0.35$ \\
Greenland (1) & $0.34 \pm 0.51$ \\
Iceland (10) & $0.72 \pm 0.09$ \\
Svalbard (6) & $0.49 \pm 0.15$ \\
Scandinavia (18) & $0.53 \pm 0.06$ \\
Central Europe (19) & $0.47 \pm 0.06$ \\
Caucasus (2) & $0.81 \pm 0.32$ \\
Central Asia (7) & $0.80 \pm 0.16$ \\
Northern Andes (4) & $0.71 \pm 0.21$ \\
Southern Andes (1) & $0.71 \pm 0.51$ \\
New Zealand (1) & $0.92 \pm 0.47$ \\
Antarctic (3) & $0.89 \pm 0.28$ \\
Global (96) & $0.68 \pm 0.12$ \\
\hline
\end{tabular}

\footnotetext{
* Error ranges give $95 \%$ confidence interval The number of observed GIC per region is shown in parentheses. The global mean is obtained by method 3 .
}

scaling the regional mean values, with each value weighted by the region's GIC area or volume. Because method 3 assumes GIC to be representative only of their regions and not of the entire Earth, it is the least likely to be geographically biased. This method, however, is limited to the past decade, because several high-mass regions had no observations in earlier decades.

The method 3 errors are dominated by errors in a few large undersampled regions, including Arctic Canada, Antarctica, Greenland, and Alaska. We estimated regional errors by 
subsampling GIC in two well-represented regions - central Europe and western Canada/US - and computing the difference between the mean $\alpha$ of each subsample and of the full sample (see Appendix B). The spread of differences as a function of subsample size (Fig. 6) gives an estimate of the error $\delta \alpha$ in poorly sampled regions with small area (e.g., New Zealand, Caucasus, and Svalbard). For poorly sampled regions with large area (e.g., Greenland, Arctic Canada, the Russian Arctic, and Antarctica, whose glaciers experience different climate regimes within the region) we carried out the same analysis but using two combined regions: (1) central Europe and Scandinavia, and (2) western Canada/US and Alaska. All errors are derived as root-mean-square errors (RMSE) at $95 \%$ confidence interval.

Figure 7 shows pentadal average global glacier mass balance for 1971-2010 as estimated by each method (see Sheet D of the supplementary material), along with the estimates of Kaser et al. (2006), Cogley (2012), and Gardner et al. (2013). (No published benchmarks exist for global average $\alpha$. However, $\alpha$ and mass balance are closely correlated, as shown in Fig. 8, suggesting that a method that is representative for mass balance is also representative for $\alpha$.) The multidecade time series in Fig. 7 show significant trends toward more negative mass balance. The estimates of Cogley (2012) are based on both geodetic and direct measurements and are more negative by $100-200 \mathrm{~kg} \mathrm{~m}^{-2} \mathrm{yr}^{-1}$ than the direct-only estimates from Kaser et al. (2006), probably because the direct measurements exclude rapidly thinning calving glaciers (Cogley, 2009a). Gardner et al. (2013), who combined satellite observations with local glaciological measurements, estimated a mass balance of $-350 \pm 40 \mathrm{~kg} \mathrm{~m}^{-2} \mathrm{yr}^{-1}$ for 20032009 , more than $100 \mathrm{~kg} \mathrm{~m}^{-2} \mathrm{yr}^{-1}$ less negative than the other published estimates for the past decade. They found that local measurements tend to be negatively biased compared to satellite-based measurements.

Method 1 (the mean of all observed GIC) gives a post2000 mass balance more negative than the published estimates, suggesting a bias due to high melt rates in overrepresented low-mass regions. Method 2 (the mean from high-mass regions) agrees closely with the direct-based estimates of Kaser et al. (2006) and, as expected, gives a less negative mass balance than the direct-plus-geodetic estimates of Cogley (2012). Method 3 (based on regional upscaling) agrees closely with method 2 in 2001-2005 and 20062010, but with large uncertainty ranges due to propagation of errors from undersampled high-mass regions. Both method 2 and method 3 give mass balances more negative than that of Gardner et al. (2013) during the past decade.

This comparison suggests that to a good approximation, methods 2 and 3 are globally representative for glacier mass balance (and hence $\alpha$ ), but with two caveats. First, the direct-plus-geodetic results of Cogley (2012) imply that the exclusion of calving glaciers could result in a positive bias of 100 to $200 \mathrm{~kg} \mathrm{~m}^{-2} \mathrm{yr}^{-1}$. On the other hand, the results of Gardner et al. (2013) suggest that mass loss in-
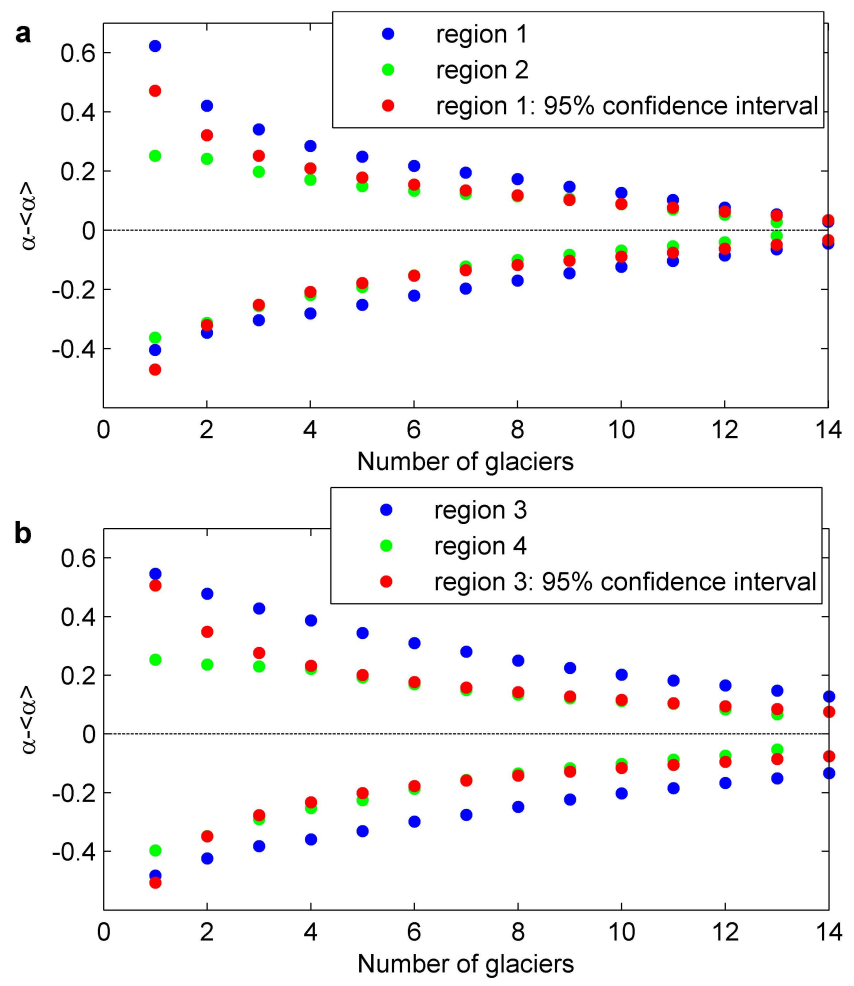

Fig. 6. Spread of decadal mean $\alpha$ as a function of subsample size in well-sampled regions. This plot shows the maximum difference between subsample mean $\alpha$ and reference $\langle\alpha\rangle$ as a function of the number of glaciers in the subsample for (a) two well-sampled regions: region 1, central Europe; and region 2, western Canada/US. (b) The same regions but extended: region 3, central Europe and Scandinavia; and region 4, western Canada/US and Alaska. The reference $\langle\alpha\rangle$ is the mean of the full sample, which includes glaciers with continuous AAR series during the period 2001-2010. In red is the difference range at $95 \%$ confidence interval $(1.96 \times$ standard deviation) for region 1 and region 3 .

ferred from direct measurements is negatively biased compared to satellite measurements. The Gardner et al. (2013) estimate of $350 \pm 40 \mathrm{~kg} \mathrm{~m}^{-2} \mathrm{yr}^{-1}$ for 2003-2009 is 100 to $150 \mathrm{~kg} \mathrm{~m}^{-2} \mathrm{yr}^{-1}$ less negative than our method 2 and 3 estimates for the past decade. A mass-balance bias of $100 \mathrm{~kg} \mathrm{~m}^{-2} \mathrm{yr}^{-1}$ would be associated with biases of about 0.06 in $p_{A}$ and 0.08 in $p_{V}$ (Fig. 8).

\section{Results and discussion}

To estimate committed GIC area and volume losses based on present-day climate, we applied method 3 to observations of $\alpha$ from 2001 to 2010. A window of about a decade is optimal because it is long enough to average over interannual variability but short compared to glacier dynamic timescales. We adjusted for geographic bias by weighting each regional mean value by the region's total GIC area (for computing $p_{A}$ ) or volume (for computing $p_{V}$ ), based on Radić et al. (2013). 


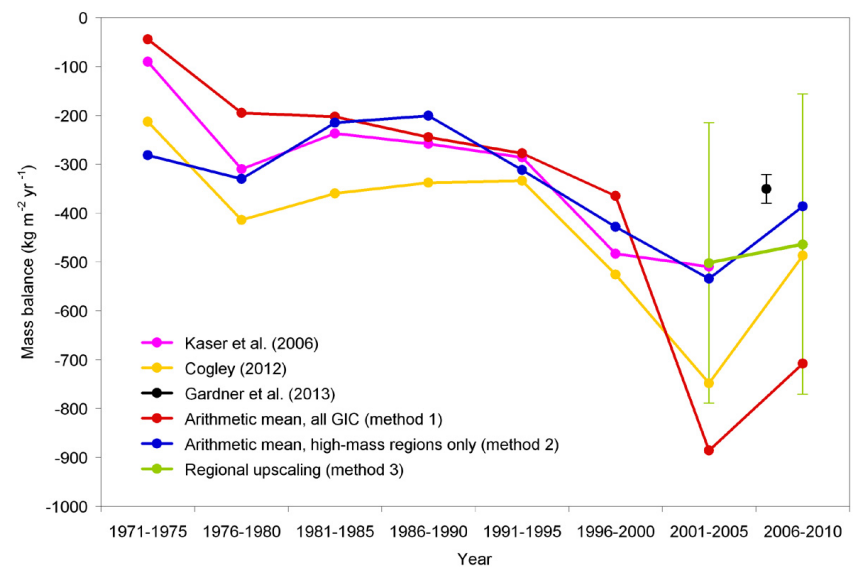

Fig. 7. Pentadal average mass balance, 1971-2010. Estimated global average GIC mass balance $\left(\mathrm{kg} \mathrm{m}^{-2} \mathrm{yr}^{-1}\right)$ at $5 \mathrm{yr}$ intervals from published estimates and from this data set: (1) Kaser et al. (2006), based on direct glacier measurements (purple); (2) Cogley (2012), based on direct plus geodetic measurements (yellow); (3) Gardner et al. (2013), with 95\% confidence interval for 20032009 (black); (4) arithmetic mean of all GIC in the 1971-2010 data set (method 1, red); (5) arithmetic mean of GIC in the eight highmass regions of Fig. 1 (method 2, blue); (6) average based on areaweighted upscaling of regional means (method 3, green) including error bars at $95 \%$ confidence interval.

Errors were estimated based on the number of observed GIC per region, and are dominated by a few underrepresented regions (see Appendix B). We found $\alpha=0.68 \pm 0.12$ for 20012010 , implying committed area losses of $32 \pm 12 \%$ and volume losses of $38 \pm 16 \%$ if climate conditions of 2001-2010 continue in the future. The resulting sea-level rise scales linearly with the initial glacier volume. Assuming a total GIC volume of $430 \mathrm{~mm}$ sea-level equivalent (SLE) (Huss and Farinotti, 2012), these committed glacier losses would raise global mean sea level by $163 \pm 69 \mathrm{~mm}$. Using a larger value of $522 \mathrm{~mm}$ SLE (Radić et al., 2013), global mean sea level would rise by $198 \pm 84 \mathrm{~mm}$.

Method 2 yields similar estimates. The mean $\alpha$ during the period 2001-2010 for GIC in high-mass regions is $0.70 \pm 0.10$, implying committed area losses of $30 \pm 10 \%$ and volume losses of $37 \pm 12 \%$ (where the error estimates are based on the assumption that these GIC are globally representative). The close agreement with method 3 suggests that method 2 does not have a large geographic bias with respect to $\alpha$.

The Earth is expected to warm further (e.g., Meehl et al., 2007), making it likely that long-term GIC area and volume losses will exceed estimates based on the climate of the past decade. From method 2, there is a significant negative trend ( $p<0.01$, based on a $t$ test) in average annual $\alpha$ of $-0.0052 \pm 0.0033 \mathrm{yr}^{-1}$ from 1971 to 2010 (Fig. 4). The trend is nearly identical for the subset of GIC with observations in all four decades, implying that the changing com-

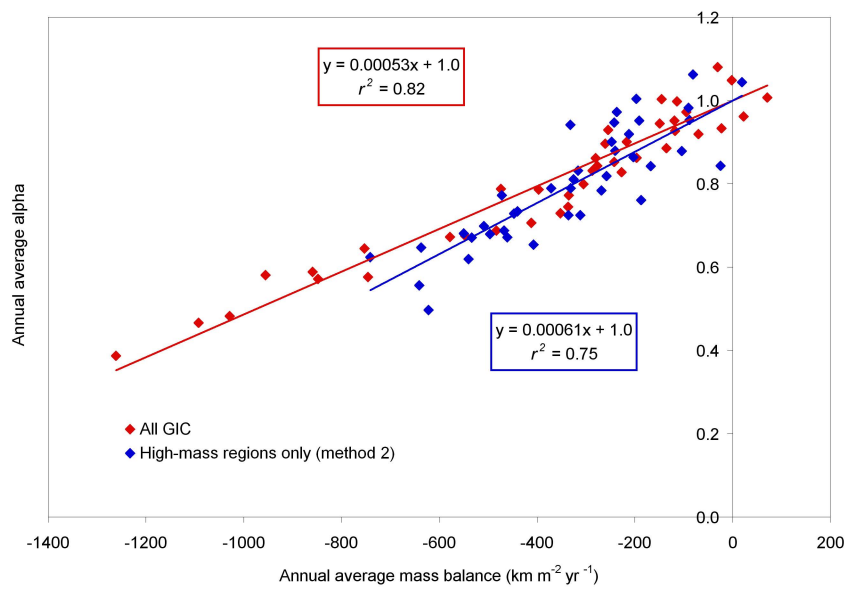

Fig. 8. Linear relation between average mass balance and average $\alpha$ for the period 1971-2010. Each diamond represents the average of all GIC observations for one year. The red diamonds denote averages over the full data set, and the blue diamonds denote averages over the GIC in high-mass regions only. The regression lines are forced to pass through the point $(x, y)=(0,1)$. Both correlations are significant $(p<0.01)$, as determined from the squared correlation coefficient, $r^{2}$. A change in mass balance of $100 \mathrm{~kg} \mathrm{~m}^{-2} \mathrm{yr}^{-1}$ is associated with a change in $\alpha$ of about 0.06 .

position of the data set does not substantially bias the trend. The trend in $\alpha$ has been much steeper since 1990; there is a significant negative trend ( $p<0.01$, based on a $t$ test) of $-0.0078 \pm 0.0082 \mathrm{yr}^{-1}$ for $1991-2010$, whereas the 19711990 trend is not significantly different from zero $(p>0.10)$. By extrapolating these trends, we can estimate the losses required to equilibrate with the climate of future decades. Taking $\alpha=0.68 \pm 0.12$ as the 2005 value and extending the $40 \mathrm{yr}$ trend, the average would fall by $0.18 \pm 0.12$ over $35 \mathrm{yr}$, reaching $0.50 \pm 0.17$ by 2040 . The Earth's GIC would then be committed to losing $50 \pm 17 \%$ of their area and $60 \pm 20 \%$ of their volume (see Appendix A). Relative to present-day GIC volume, which is decreasing by about $2 \%$ per decade, the losses would be somewhat greater. These error ranges may understate the true uncertainties because of natural interdecadal variability, and because the method 2 data set may not be globally representative.

Glacier area and volume losses will occur on decade-tocentury timescales. The AAR method does not directly predict rates of retreat and thinning, but theory (Jóhannesson et al., 1989) predicts that the volume response time for a typical glacier with a mean thickness of $100-500 \mathrm{~m}$ is on the order of 100 years. Scaling analysis (Bahr and Radić, 2012) implies that glaciers thinner than $500 \mathrm{~m}$ contain a majority of the Earth's total glacier volume (see Appendix C), suggesting that a large fraction of committed glacier volume losses will occur within a century. However, larger GIC with longer response times will continue to lose mass and raise sea level after 2100 . 


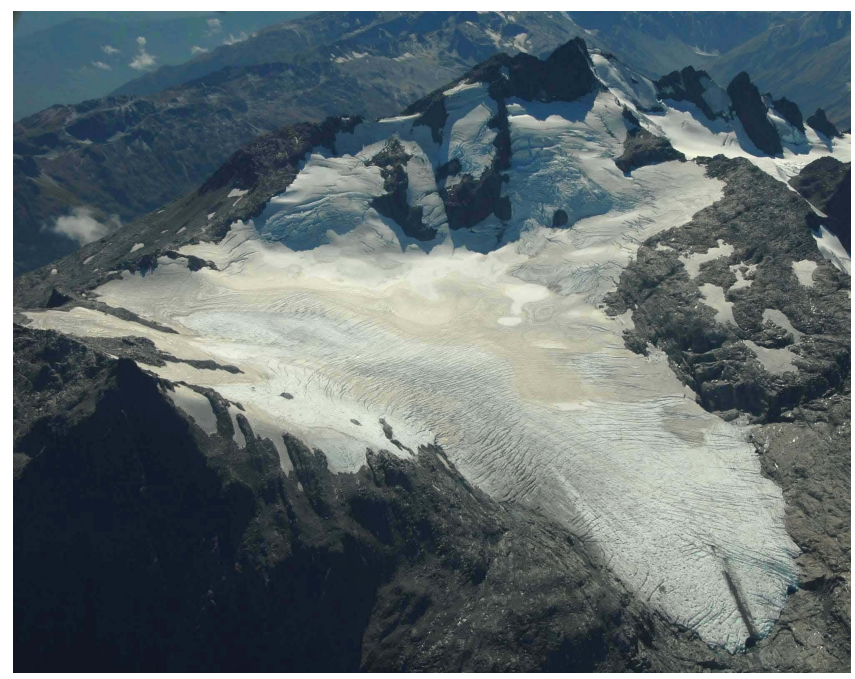

Fig. 9. Brewster Glacier, New Zealand, at the end of the 2008 ablation season. The glacier area is $2.5 \mathrm{~km}^{2}$. The 2008 glacier mass balance is $-1653 \mathrm{~kg} \mathrm{~m}^{-2} \mathrm{yr}^{-1}$, and the AAR is $10 \%$, with net accumulation limited to small white patches of remaining snow. Grey firn areas (i.e., snow from previous years) generally lie in the ablation zone, as does the bare (blue) ice. The photo illustrates the difficulty of determining a specific elevation at which a glacier is in equilibrium. Photo taken by A. Willsman (Glacier Snowline Survey, National Institute of Water and Atmospheric Research Ltd (NIWA), New Zealand), 14 March 2008.

This analysis has focused on global ice losses and sealevel rise, but glacier retreat and thinning will also have regional impacts associated with changes in seasonal runoff (Immerzeel et al., 2010; Kaser et al., 2010) and glacier hazards (Kääb et al., 2005). In some regions, fractional area and volume ice losses will exceed the global average. Assuming that the observed GIC are regionally representative, GIC in central Europe will lose $64 \pm 7 \%$ of their volume if future climate resembles the climate of the past decade (which included several record heat waves). We also project substantial volume losses in Scandinavia $(56 \pm 7 \%)$, western Canada/US $(53 \pm 7 \%)$ and Iceland $(35 \pm 11 \%)$. Projections elsewhere are less certain because of the smaller sample sizes.

\section{Conclusions}

AARs are declining faster than most glaciers and ice caps (GIC) can respond dynamically. As a result, committed area and volume losses far exceed the losses observed to date. Based on regional upscaling of AAR observations from 2001 to 2010, we conclude that the Earth's glaciers and ice caps will ultimately lose $32 \pm 12 \%$ of their area and $38 \pm 16 \%$ of their volume if the future climate resembles the climate of the past decade. Committed losses could increase substantially during the next few decades if the climate continues to warm.
These relative losses are larger than those estimated by BDM, reflecting the lower AARs in data that have become available since the earlier study. Our projections, however, have large uncertainties ( $40 \%$ relative error in the projected mass loss) that are dominated by underrepresented high-mass regions, including Arctic Canada, Antarctica, Greenland, and Alaska.

To reduce the uncertainties, more observations are needed in poorly sampled regions. Direct mass-balance and AAR measurements are inherently labor intensive and limited in coverage. AARs can be estimated, however, from aerial and satellite observations of the end-of-summer snowline (e.g., Fig. 9 and Rabatel et al., 2013). Deriving $\mathrm{AAR}_{0}$ from observations requires mass-balance measurements for about a decade, but BDM found that the global mean $\mathrm{AAR}_{0}$ can be used for most GIC with only moderate loss of precision. Huss et al. (2013) recently showed that simple mass balance modeling, combined with terrestrial and airborne/spaceborne AAR observations, can be used to determine glacier mass changes. Also, AAR methods could be extended to tidewater glaciers, incorporating calving as well as surface processes.

\section{Appendix A}

\section{Means and errors of $\alpha, p_{A}$, and $p_{V}$}

The first section of Sheet $\mathrm{C}$ in the supplementary material (All GIC - alpha, $\left.p_{A}, p_{V}\right)$ shows values of $\alpha=\mathrm{AAR} / \mathrm{AAR}_{0}$ for the full data set. For each year $i$, the annual mean $\alpha$ is found by averaging over $N_{i}$ values:

$\bar{\alpha}_{i}=\frac{\sum_{n=1}^{N_{i}} \alpha_{n i}}{N_{i}}$,

where $\alpha_{n i}$ denotes the value for glacier $n$ in year $i$. The variance for each year is computed as

$\sigma_{i}^{2}=\frac{1}{N_{i}-1} \sum_{n=1}^{N_{i}}\left(\alpha_{n i}-\bar{\alpha}_{i}\right)^{2}$,

resulting in a standard error of

$\delta \alpha_{i}=\frac{\sigma_{i}}{\sqrt{N_{i}}}$.

The annual values and running $10 \mathrm{yr}$ means are shown in Fig. 4.

Arithmetic means for the full data set were computed for four $10 \mathrm{yr}$ windows: 1971-1980, 1981-1990, 1991-2000, and 2001-2010. For the full data set we computed a mean $\alpha$ of $0.93 \pm 0.06,0.85 \pm 0.06,0.83 \pm 0.07$, and $0.59 \pm 0.05$ during the 1970s, 1980s, 1990s, and 2000s, respectively. Let us suppose that for a given glacier $n$, we have measurements in $M_{n}$ out of $10 \mathrm{yr}\left(1 \leq M_{n} \leq 10\right)$. In order for each measurement to be weighted equally, glaciers with more measurements receive greater weight than those with fewer measurements. Thus the decadal mean for the data set is computed as 

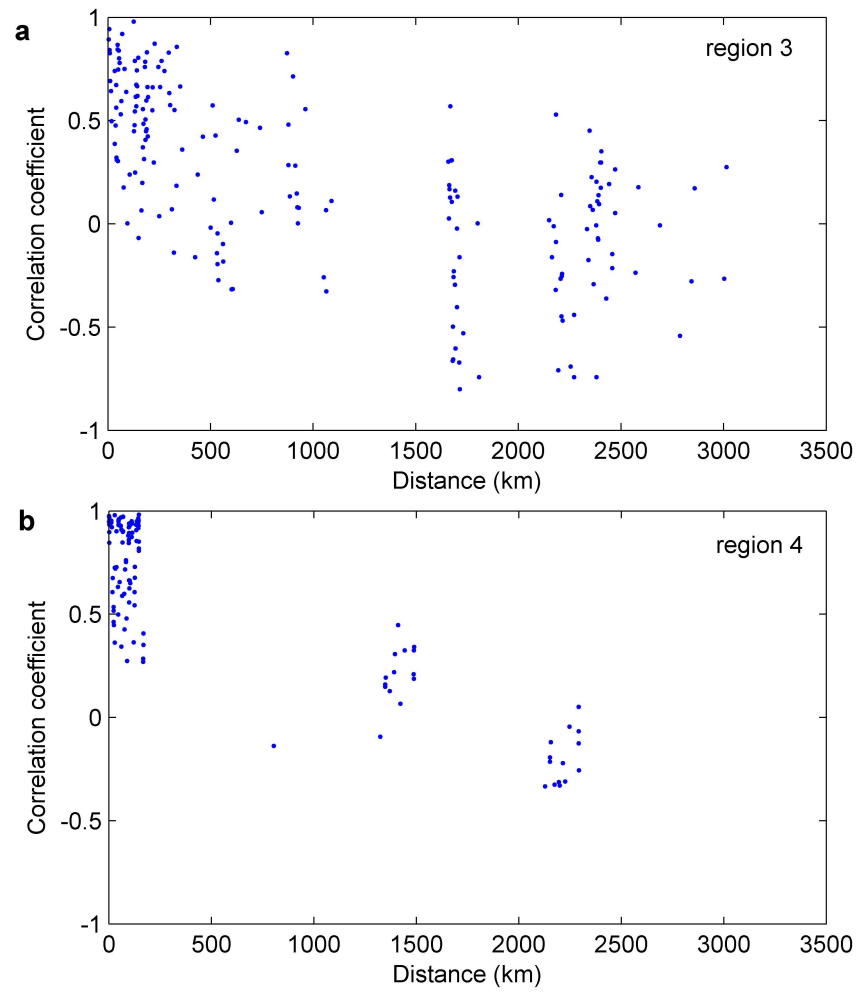

Fig. A1. Correlation between $\alpha$ time series (2001-2010) of any two glaciers in a region versus the distance between the two glaciers. (a) Region 3: central Europe (15 glaciers) and Scandinavia (5 glaciers); (b) region 4: western Canada/US (14 glaciers) and Alaska (2 glaciers).

$\bar{\alpha}=\frac{\sum_{n=1}^{N} f_{n} \bar{\alpha}_{n}}{N_{f}}$,

where $f_{n}=M_{n} / 10, \bar{\alpha}_{n}$ is given by

$\bar{\alpha}_{n}=\frac{\sum_{i=1}^{M_{n}} \alpha_{n i}}{M_{n}}$,

and

$N_{f}=\sum_{n=1}^{N} f_{n}$.

Equation (A4) is equivalent to the arithmetic mean of all measurements, with each measurement weighted equally. We can think of $N_{f}$ as the equivalent number of glaciers; it is equal to the total number of measurements divided by the number of years. The variance is given by

$\sigma^{2}=\frac{1}{N_{f}-1} \sum_{n=1}^{N} f_{n}\left(\bar{\alpha}_{n}-\bar{\alpha}\right)^{2}$ and the standard error is

$\delta \alpha=\frac{\sigma}{\sqrt{N_{f}}}$.

The arithmetic mean AAR and its standard error, shown in the second section of Sheet C for 2001-2010 only, are computed analogously.

The next sections of Sheet $C$ show the 2001-2010 arithmetic mean values of $p_{A}$ and $p_{V}$ for the full data set. BDM showed that for a given glacier or ice cap, $p_{A}=\alpha-1$ and $p_{V}=\alpha^{\gamma}-1$, where $\alpha=\mathrm{AAR} / \mathrm{AAR}_{0}$ and $\gamma$ is the exponent in the glacier volume-area scaling relationship, $V=c A^{\gamma}$ (Bahr et al., 1997). Data and theory suggest $\gamma=1.25$ for ice caps and $\gamma=1.375$ for glaciers. Thus $p_{V}$ depends on $\gamma$ but not on the poorly constrained constant $c$, and $p_{A}$ is independent of both $c$ and $\gamma$. We compute means of $p_{A}$ and $p_{V}$ first for glaciers, then separately for ice caps. (In the text below, we generally refer to "glaciers", but the same analysis applies to ice caps with the appropriate value of $\gamma$.) For a single glacier we have $\bar{p}_{A n}=\bar{\alpha}_{n}-1$ and $\bar{p}_{V n}=\bar{\alpha}_{n}^{\gamma}-1$, where $\bar{\alpha}_{n}$ is the mean value of $\alpha$ for glacier $n$ over the decade. Let us suppose we have at least one $\alpha$ value during the decade for each of $N$ glaciers. To give greater weight to glaciers with more measurements, we compute the decadal mean $\bar{p}_{A}$ and $\bar{p}_{V}$ as

$\bar{p}_{A}=\frac{\sum_{n=1}^{N} f_{n} \bar{\alpha}_{n}}{N_{f}}-1$

and

$\bar{p}_{V}=\frac{\sum_{n=1}^{N} f_{n} \overline{\alpha_{n}^{\gamma}}}{N_{f}}-1$.

The variance associated with $p_{A}$ is

$\sigma_{p_{A}}^{2}=\frac{1}{N_{f}-1} \sum_{n=1}^{N} f_{n}\left(\bar{\alpha}_{n}-\bar{\alpha}\right)^{2}$,

and the variance associated with $p_{V}$ is

$\sigma_{p_{V}}^{2}=\frac{1}{N_{f}-1} \sum_{n=1}^{N} f_{n}\left(\overline{\alpha_{n}^{\gamma}}-\overline{\alpha^{\gamma}}\right)^{2}$.

The standard errors are

$\delta p_{A}=\frac{\sigma_{p_{A}}}{\sqrt{N_{f}}}$

and

$\delta p_{V}=\frac{\sigma_{p_{V}}}{\sqrt{N_{f}}}$.

If these data are taken to be globally representative, as assumed by BDM, then we compute that the Earth's glaciers 
must lose $44 \pm 6 \%$ of their area and $51 \pm 7 \%$ of their volume, and ice caps must lose $32 \pm 9 \%$ of their area and $38 \pm 10 \%$ of their volume, in order to reach equilibrium with the climate of the past decade. As discussed in the main text, however, the data are likely to be geographically biased.

To assess the data for size biases, we plotted the mean value of $\alpha$ for each glacier against the $\log$ of glacier area. As shown in Fig. 5, the correlation is slightly positive $\left(r^{2}=\right.$ $0.03)$ but statistically insignificant $(p<0.10)$. The correlation between $\alpha$ and glacier area is also insignificant. A positive correlation between glacier area and the change in $\alpha$ (relative to the equilibrium value of 1.0) would be expected in the following case: if (1) larger glaciers have greater elevation ranges than smaller glaciers; (2) for a given lifting of the equilibrium line altitude (ELA), the AAR decreases less for glaciers with large elevation ranges than for glaciers with small elevation ranges; and (3) the average lifting of the ELA in a warming climate is independent of glacier size. The lack of a significant correlation between glacier area and $\alpha$ suggests that one or more of these assumptions does not apply to the observed GIC. We checked for area-range bias (i.e., the first assumption) by comparing plots of glacier area vs. elevation range for (1) the observed GIC and (2) more than 100000 GIC in the World Glacier Inventory (Cogley et al., 2009b). We did not find evidence of a significant bias.

Sheet $\mathrm{E}$ in the supplementary material (High mass regions) is similar to Sheet C except that it includes only the 38 GIC in high-mass regions: Arctic Canada, Antarctica, Alaska, Greenland, the Russian Arctic, central Asia, Svalbard, and the southern Andes. The first three sections show AAR, mass balance, and $\alpha$, respectively. Decadal mean values of $\alpha, p_{A}$, and $p_{V}$ as well as the associated standard errors are shown for 2001-2010. These are the "method 2" averages cited in the text. The arithmetic mean and $10 \mathrm{yr}$ running mean are shown in Fig. 4, and the $40 \mathrm{yr}$ linear trend (1971-2010) and two $20 \mathrm{yr}$ linear trends (1971-1990 and 1991-2010) of the mean values are given in Sheet E. We used a $t$ test to determine significance. The 1970-2009 and 1990-2009 trends are significantly negative at the $1 \%$ level, whereas the 1970 1989 trend is not significantly different from zero at the $10 \%$ level. In the last section of Sheet E, we repeated the annual mean and trend calculations for the 11 GIC in high-mass regions with observations in all four decades to assess the effect on the trends of the changing composition of the data set. The trends are similar to those computed for all 38 GIC.

To estimate future values of the global mean $\alpha$, we took $\alpha_{\text {global }}=0.68 \pm 0.12$ (the global mean value estimated for 2001-2010, given in Section 3) as a best estimate for 2005. We applied the $40 \mathrm{yr}$ trend $\left(-0.0052 \pm 0.0033 \mathrm{yr}^{-1}\right)$ given in Sheet $\mathrm{E}$ for the 38 high-mass GIC (method 2). Extending this trend for $35 \mathrm{yr}$ gives a change of $-0.18 \pm 0.12$, resulting in $\alpha_{\text {global }}=0.50 \pm 0.17$ by 2040 . (It is possible that the downward trend in $\alpha$ would slow as $\alpha$ reaches 0 for an increasing number of glaciers. With this $35 \mathrm{yr}$ mean trend, however, only three of 96 glaciers with data in 2001-2010 would have $\alpha=0$ by 2040 , with a negligible effect on the results.) We set $p_{V \text { global }}=\left(\bar{\alpha}_{\text {global }}\right)^{\bar{\gamma}}-1$, with $\bar{\gamma}=1.31 \pm 0.05$ to reflect an uncertain partitioning of volume between glaciers and ice caps. The error $\delta_{P v}$ global $=0.20$ was calculated as

$\left(\delta p_{V}\right)^{2}=\left(\frac{\partial p_{V}}{\partial \alpha}\right)_{\bar{\alpha}}^{2}(\delta \alpha)^{2}+\left(\frac{\partial p_{V}}{\partial \gamma}\right)_{\bar{\gamma}}^{2}(\delta \gamma)^{2}$.

\section{Appendix B}

\section{Regional calculations}

Sheet $\mathrm{F}$ (Regional mass balance) shows the average mass balance during the period 2001-2010 for each of 14 regions (Table 1), the estimated GIC area in the region (Radić et al., 2013), and the corresponding fraction of the Earth's total GIC area. For the past decade the data set has no observations from the Russian Arctic, which contains an estimated $8 \%$ of global GIC area, or from North Asia, which contains much less than $1 \%$. For purposes of regional upscaling, we used Svalbard (which is climatically similar) as a surrogate for the Russian Arctic, and we neglected North Asia. Thus the regional area fractions are relative to a global total that omits the small GIC area in North Asia. The global average mass balance is computed as

$b_{\text {global }}=\sum_{n} w_{A n} b_{n}$,

where $w_{A n}$ is the fractional area weight for region $n$, and $b_{n}$ is the mean mass balance. Sheet $F$ shows the global average mass balance computed for the full decade, for each of two pentads, and for the period 2003-2009 (corresponding to Gardner et al., 2013).

Sheet G (Regional alpha) shows regional mean values of $\alpha$ in 2001-2010 for the same 14 regions (Table 1 in the main text) based on Radić et al. (2013). Again, Svalbard is used as a surrogate for the Russian Arctic, and North Asia is neglected. Decadal mean $\alpha$ for each glacier and ice cap are shown in Sheet G. Measurements of $\alpha$ are averaged, with each measurement weighted equally, to obtain the regional means $\bar{\alpha}_{n}$. The estimated area and volume losses per region are $\bar{p}_{A n}=\bar{\alpha}_{n}-1$ and $\bar{p}_{V n}=\left(\bar{\alpha}_{n}\right)^{\bar{\gamma}_{n}}-1$, where $\bar{\gamma}_{n}$ is estimated as described below. The upscaled global estimates are obtained by summing over regions, with each regional value weighted by the estimated total GIC area in the region (for $\alpha$ and $p_{A}$ ) and total volume (for $p_{V}$ ):

$p_{A \text { global }}=\sum_{n} w_{A n} \bar{p}_{A n}$,

$p_{V \text { global }}=\sum_{n} w_{V n} \bar{p}_{V n}$.

The upscaled values, with errors, are shown in Sheet G. The regional area and volume weights, $w_{A n}$ and $w_{V n}$, are also shown in Sheet G. 
The errors for these global estimates are given by

$\left(\delta p_{A \text { global }}\right)^{2}=\sum_{n}\left(w_{A n} \delta p_{A n}\right)^{2}$

$\left(\delta p_{V \text { global }}\right)^{2}=\sum_{n}\left(w_{V n} \delta p_{V n}\right)^{2}$,

where $\delta p_{A n}$ and $\delta p_{V n}$ are the regional errors. For each region we have $\delta p_{A n}=\delta \alpha_{n}$, where $\delta \alpha_{n}$ (shown in column $\mathrm{V}$ ) is estimated by the following method. We subsampled GIC in two well-represented regions, central Europe and western Canada/US. For 2001-2010 we considered $n=15$ glaciers with continuous records in central Europe, and $n=$ 14 glaciers with continuous records in western Canada/US. The full samples per region provide reference mean values $\langle\alpha\rangle$ for each region. For each region we computed means for all possible subsamples containing 1 to $n-1$ glaciers. For a subsample of one glacier, regional $\alpha$ is equal to $\alpha$ from each glacier, and therefore this subsample gives the largest range of possible values. We also calculated the regional mean $\alpha$ for all possible subsamples of two glaciers, three glaciers, and so on. For each subsample size, Fig. 6a shows the maximum range of results (i.e., subsampled regional $\alpha$ minus the reference $\langle\alpha\rangle$ ). The range is largest for a subsample of one glacier and slowly decreases as we approach the maximum of 14 glaciers (and would reach zero for the total of 20 in this case). For each subsample size we computed the standard deviation of the $\alpha$ values. Figure 6 a shows the $95 \%$ confidence interval $(1.96 \times$ standard deviation), which provides an estimate of $\delta \alpha_{n}$ in poorly sampled regions with small spatial area (Iceland, Svalbard, the northern Andes, the Caucasus, and New Zealand). For regions containing more than 10 glaciers with observed AAR (central Europe, Scandinavia and western Canada/US) we assigned an error based on a subsample size of 12. (A number $>10$ was chosen arbitrarily, but the error does not decline significantly for sample sizes $>10$; any number from 11 to 14 would give a similar error estimate.) Based on the data from central Europe, which has a wider spread of differences than western Canada/US, the errors (values of $n$ shown in parentheses) are as follows: Iceland (10), $\delta \alpha=0.09$; Svalbard (6), $\delta \alpha=0.15$; the northern Andes (4), $\delta \alpha=0.21$; Caucasus (2), $\delta \alpha=0.32$; New Zealand (1), $\delta \alpha=0.47$; and central Europe (19), Scandinavia (18), and western Canada/US (18), $\delta \alpha=0.06$.

For poorly sampled regions covering large spatial area (central Asia, Alaska, Antarctica, Arctic Canada, the southern Andes, and Greenland), we carried out the same analysis but using two combined regions: (1) central Europe and Scandinavia, and (2) western Canada/US and Alaska (Fig. 6b). Thus, in addition to $n=15$ glaciers from central Europe we included $n=5$ glaciers from Scandinavia, and in addition to $n=14$ glaciers from western Canada/US we included $n=2$ glaciers from Alaska. For each of these two extended regions we carried out a correlation analysis.
Although there are a few correlations of $\sim 0.5$ for glaciers $>1500 \mathrm{~km}$ apart, most time series of $\alpha$ are not significantly correlated when the distance between glaciers exceeds $\sim 300$ $\mathrm{km}$ (Fig. A1). Therefore, the glacier sampling in the combined regions is representative for poorly sampled regions covering large spatial areas whose glaciers experience different climatic regimes within the region. Based on the data from central Europe and Scandinavia (which has a wider spread of differences than western Canada/US and Alaska), the errors at $95 \%$ confidence interval (values of $n$ shown in parentheses) are as follows: central Asia (7), $\delta \alpha=0.16$; Alaska and Antarctica (3), $\delta \alpha=0.28$; Arctic Canada (2), $\delta \alpha=0.35$; and Greenland and the southern Andes (1), $\delta \alpha=$ 0.51 .

Since $p_{V}$ is a function of both $\alpha$ and $\gamma$, the regional errors $\delta p_{V n}$ depend on both $\delta \alpha_{n}$ and $\delta \gamma_{n}$ :

$$
\left(\delta p_{V n}\right)^{2}=\left(\frac{\partial p_{V}}{\partial \alpha}\right)_{\bar{\alpha}_{n}}^{2}\left(\delta \alpha_{n}\right)^{2}+\left(\frac{\partial p_{V}}{\partial \gamma}\right)_{\bar{\gamma}_{n}}^{2}\left(\delta \gamma_{n}\right)^{2},
$$

where $\bar{\alpha}$ and $\bar{\gamma}$ are best estimates. Evaluating the derivatives, this becomes

$$
\left(\delta p_{V n}\right)^{2}=\left(\bar{\gamma}_{n} \bar{\alpha}_{n}^{\bar{\gamma}-1}\right)^{2}\left(\delta \alpha_{n}\right)^{2}+\left(\bar{\alpha}_{n}^{\bar{\gamma}} \ln \left(\bar{\alpha}_{n}\right)\right)^{2}\left(\delta \gamma_{n}\right)^{2} .
$$

We estimated $\bar{\gamma}_{n}$ and $\delta \gamma_{n}$ as follows. Drawing from existing glacier inventories (Cogley, 2009b), we tabulated the total number of GIC and the number of ice caps in each region. Regions with relatively few ice caps (less than $1 \%$ of the total number of GIC in the regional inventory) were assumed to have most of their volume contained in glaciers. For these regions we assumed $\bar{\gamma}=1.36 \pm 0.02$, where the error corresponds roughly to the difference between the observed value of 1.36 for valley glaciers and the theoretical value (Bahr et al., 1997) of 1.375. For regions where at least $1 \%$ of the GIC are classified as ice caps, we assumed $\bar{\gamma}=1.31 \pm 0.05$ to reflect an uncertain partitioning of volume between glaciers and ice caps. (Because ice caps can be much larger than typical glaciers, a relatively small number of ice caps can contain a substantial fraction of a region's volume. BDM, for example, estimated that $53 \%$ of total GIC volume is contained in ice caps and $47 \%$ in glaciers, although there are many more glaciers than ice caps.) A more complete analysis would use scaling relationships to estimate the total glacier and ice cap volume in each region. Existing inventories, however, do not contain complete lists of glaciers and ice caps in all regions, nor do all GIC fall clearly into one category or the other.

Although the partitioning between glaciers and ice caps is only approximate, our results are not sensitive to the details of this partitioning. The errors $\delta p_{V n}$ are dominated by the term containing $\delta \alpha_{n}$ (the first term on the right-hand side of Eq. B6), with much smaller contributions from the term containing $\delta \gamma_{n}$ (the second term on the right-hand side of Eq. B6). 


\section{Appendix C}

\section{Glacier volume response times}

The volume response time for a glacier, defined as the timescale for exponential adjustment to a new steady-state volume following a mass-balance perturbation, can be estimated as $\tau_{V} \sim H /\left|b_{\mathrm{T}}\right|$, where $H$ is a thickness scale (e.g., mean glacier thickness) and $b_{\mathrm{T}}$ is the mass balance at the terminus (Jóhannesson et al., 1989). For typical glaciers with thicknesses of 100 to $500 \mathrm{~m}$ and terminus melt rates of 1 to $5 \mathrm{~m} \mathrm{yr}^{-1}$, the response time is on the order of $100 \mathrm{yr}$. The mean terminus melt rate for our data set is $\sim 3 \mathrm{~m} \mathrm{yr}^{-1}$, as shown in Sheet I (Terminus mass balance).

Bahr and Radic (2012) showed that the fraction of total volume contained in glaciers of area less than $A_{\min }$ is given to a good approximation by

$\Theta=\left(\frac{A_{\min }}{A_{\max }}\right)^{\gamma-\beta+1}$,

where $A_{\max }$ is the area of the largest glaciers; $\gamma=1.375$ is the exponent in the volume-area scaling relationship $V \propto$ $A^{\gamma}$; and $\beta=2.1$ is the exponent in the power law $N(A) \propto$ $A^{-\beta}$, which predicts the number of glaciers $N$ of size $A$. Volume-area scaling implies $h \propto A^{\gamma-1}$, where $h$ is the mean ice thickness. Therefore,

$\Theta=\left(\frac{h_{\min }}{h_{\max }}\right)^{\frac{\gamma-\beta+1}{\gamma-1}}$.

The largest glaciers and ice caps have a thickness of about $1000 \mathrm{~m}$. Setting $h_{\min }=500 \mathrm{~m}$ and $h_{\max }=1000 \mathrm{~m}$ in Eq. (A24), we obtain $\Theta=0.60$, implying that approximately $60 \%$ of total glacier volume resides in glaciers thinner than $500 \mathrm{~m}$. This analysis suggests that glaciers with response times on the order of a century or less contain a majority of the Earth's total glacier volume.

\section{Appendix D}

\section{Contributing investigators}

The principal investigators for the glaciers and ice caps in the WGMS database are listed in WGMS (2012) and earlier bulletins. We have supplemented the WGMS database with data compiled by Mark Dyurgerov (Dyurgerov et al., 2005; Bahr et al., 2009). In addition, we thank the following investigators for providing us with data not previously in the WGMS database:

- Pedro Skvarca: Bahia Del Diablo

- Andrea Fischer and Gerhard Markl: Hintereisferner, Jamtalferner, Kesselwandferner
- Heinz Slupetzky: Sonnblickkees

- Ludwig N. Braun: Vernagtferner

- Reinhard Böhm and Wolfgang Schöner: Goldbergkees, Kleinfleißkees, Wurtenkees

- Javier C. Mendoza Rodríguez and Bernard Francou: Charquini Sur, Zongo

- Alex Gardner: Devon Ice Cap NW

- Graham Cogley: White

- Bolívar Cáceres Correa and Bernard Francou: Antizana 15 Alpha

- Niels Tvis Knudsen: Mittivakkat

- Finnur Pálsson, Helgi Björnsson, and Hannes Haraldsson: Brúarjökull, Eyjabakkajökull, Köldukvíslarjökull, Langjökull S. Dome, Tungnaárjökull

- Porsteinn Porsteinsson: Hofsjökull N, Hofsjökull E, Hofsjökull SW

- Luca Carturan: Carèser

- Luca Mercalli: Ciardoney

- Gian Carlo Rossi and Gian Luigi Franchi: Malavalle, Pendente

- Bjarne Kjøllmoen: Ålfotbreen, Breidalblikkbrea, Gråfjellsbrea, Langfjordjøkelen, Nigardsbreen

- Hallgeir Elvehøy: Austdalsbreen, Engabreen, Hardangerjøkulen

- Liss M. Andreassen: Gråsubreen, Hellstugubreen, Storbreen

- Jack Kohler: Austre Broggerbreen, Kongsvegen, Midtre Lovénbreen

- Piotr Glowacki and Dariusz Puczko: Hansbreen

- Ireneusz Sobota: Waldemarbreen

- O.V. Rototayeva: Garabashi

- Yu K. Narozhniy: Leviy Aktru, Maliy Aktru, and No. 125

- Miguel Arenillas: Maladeta

- Peter Jansson: Mårmaglaciären, Rabots glaciär, Riukojietna, Storglaciären

- Giovanni Kappenberger and Giacomo Casartelli: Basòdino

- Martin Funk and Andreas Bauder: Gries, Silvretta 
- Mauri Pelto: Columbia (2057), Daniels, Easton, Foss, Ice Worm, Lower Curtis, Lynch, Rainbow, Sholes, Yawning, Lemon Creek

- Jon Riedel: Noisy Creek, North Klawatti, Sandalee, Silver

- Rod March and Shad O'Neel: Gulkana, Wolverine

- William R. Bidlake: South Cascade

\section{Supplementary material related to this article is available online at http://www.the-cryosphere.net/7/ 1565/2013/tc-7-1565-2013-supplement.zip.}

Acknowledgements. We thank principal investigators and their teams, along with the WGMS staff, for providing AAR and massbalance data. We also thank Daniel Farinotti, Ben Marzeion, and Mauri Pelto for insightful reviews, and we thank Graham Cogley, Alex Gardner, Matthias Huss, and Georg Kaser for helpful data and feedback. This work was supported partly by a Los Alamos National Laboratory (LANL) Director's Fellowship and by the Earth System Modeling program of the Office of Biological and Environmental Research within the US Department of Energ's Office of Science. LANL is operated under the auspices of the National Nuclear Security Administration of the US Department of Energy under contract No. DE-AC52-06NA25396, and partly by the European Community's Seventh Framework Programme under grant agreement No. 262693.

Edited by: J. O. Hagen

\section{References}

Arendt, A. A., Bolch, T., Cogley, J. G., Gardner, A., Hagen, J.O., Hock, R., Kaser, G., Pfeffer, W. T., Moholdt, G., Paul, F., Radić, V., Andreassen, L., Bajracharya, S., Beedle, M., Berthier, E., Bhambri, R., Bliss, A., Brown, I., Burgess, E., Burgess, D., Cawkwell, F., Chinn, T., Copland, L., Davies, B., de Angelis, H., Dolgova, E., Filbert, K., Forester, R., Fountain, A., Frey, H., Giffen, B., Glasser, N., Gurney, S., Hagg, W., Hall, D., Haritashya, U. K., Hartmann, G., Helm, C., Herreid, S., Howat, I., Kapustin, G., Khromova, T., Kienholz, C., Koenig, M., Kohler, J., Kriegel, D., Kutuzov, S., Lavrentiev, I., LeBris, R., Lund, J., Manley, W., Mayer, C., Miles, E., Li, X., Menounos, B., Mercer, A., Moelg, N., Mool, P., Nosenko, G., Negrete, A., Nuth, C., Pettersson, R., Racoviteanu, A., Ranzi, R., Rastner, P., Rau, F., Rich, J., Rott, H., Schneider, C., Seliverstov, Y., Sharp, M., Sigurðsson, O., Stokes, C., Wheate, R., Winsvold, S., Wolken, G., Wyatt, F., and Zheltyhina, N: Randolph Glacier Inventory [v2.0]: a Dataset of Global Glacier Outlines, digital media, available at: http://www.glims.org/RGI/RGI_Tech_Report_V2.0.pdf, Global Land Ice Measurements from Space, Boulder, Colorado, 2012.
Bahr, D. B. and Radić, V.: Significant contribution to total mass from very small glaciers, The Cryosphere, 6, 763-770, doi:10.5194/tc-6-763-2012, 2012.

Bahr, D. B., Meier, M. F., and Peckham, S. D.: The physical basis of glacier volume-area scaling, J. Geophys. Res., 102, 2035520362, 1997.

Bahr, D. B., Dyurgerov, M., and Meier, M. F.: Sea-level rise from glaciers and ice caps: A lower bound, Geophys. Res. Lett., 36, L03501, doi:10.1029/2008GL036309, 2009.

Cazenave, A. and Llovel, W.: Contemporary sea level rise, Annu. Rev. Mar. Sci., 2, 145-173, 2010.

Cogley, J. G.: Geodetic and direct mass-balance measurements: comparison and joint analysis, Ann. Glaciol., 50, 96-100, 2009a.

Cogley, J. G.: A more complete version of the World Glacier Inventory, Ann. Glaciol., 50, 32-38, 2009b.

Cogley, J. G.: The Future of the World's Glaciers, in: The Future of the World's Climate, edited by: Henderson-Sellers, A. and McGuffie, K., 197-222, Elsevier, Amsterdam, 2012.

Dyurgerov, M. B.: Data of Glaciological Studies - Reanalysis of Glacier Changes: From the IGY to the IPY, 1960-2008, Publication No. 108, Institute of Arctic and Alpine Research, Boulder, Colorado, 2010.

Dyurgerov, M. B. and Meier, M. F.: Glaciers and the Changing Earth System: A 2004 Snapshot, Occas. Paper 58, 117 pp., Institute of Arctic and Alpine Research, Boulder, Colorado, 2005.

Dyurgerov, M. B., Meier, M. F., and Bahr, D. B.: A new index of glacier area change: a tool for glacier monitoring, J. Glaciol., 55, 710-716, 2009.

Gardner, A. S., Moholdt, G., Cogley, J. G., Wouters, B., Arendt, A. A., Wahr, J., Berthier, E., Hock, R., Pfeffer, W. T., Kaser, G., Ligtenberg, S. R. M., Bolch, T., Sharp, M. J., Hagen, J. O., van den Broeke, M. R., and Paul, F. A: Reconciled estimate of glacier contributions to sea level rise: 2003 to 2009, Science, 340, 852857, 2013.

Huss, M. and Farinotti, D.: Distributed ice thickness and volume of all glaciers around the world, J. Geophys. Res., 117, F04010, doi:10.1029/2012JF002523, 2012.

Huss, M., Sold, L., Hoelzle, M., Stokvis, M., Salzmann, N., Farinotti, D., and Zemp, M.: Towards remote monitoring of sub-seasonal glacier mass balance, Ann. Glaciol., 54, 85-93, doi:10.3189/2013AoG63A427, 2013.

Immerzeel, W. W., van Beek, L. P. H., and Bierkens, M. F. P.: Climate change will affect the Asian water towers, Science, 328, 1382-1385, 2010.

Jacob, T., Wahr, J., Pfeffer, W. T., and Swenson, S.: Recent contributions of glaciers and ice caps to sea level rise, Nature, 482, 514-518, 2012.

Jóhannesson, T., Raymond, C., and Waddington, E.: Time-scale for adjustment of glaciers to changes in mass balance, J. Glaciol., 35, 355-369, 1989.

Kääb, A., Reynolds, J. M., and Haeberli, W.: Glacier and permafrost hazards in high mountains, in: Global Change and Mountain Regions: An Overview of Current Knowledge, edited by: Huber, U. M., Bugmann, H. K. M., and Reasoner, M. A., Springer, Dordrecht, the Netherlands, 225-234, 2005.

Kaser, G., Cogley, J. G., Dyurgerov, M. B., Meier, M. F., and Ohmura, A.: Mass balance of glaciers and ice caps: Consensus estimates for 1961-2004, Geophys. Res. Lett., 33, L19501, doi:10.1029/2006GL027511, 2006. 
Kaser, G., Großhauser, M., and Marzeion, B.: Contribution potential of glaciers to water availability in different climate regimes, $\mathrm{P}$. Natl. Acad. Sci. USA, 107, 20223-20227, 2010.

Marzeion, B., Jarosch, A. H., and Hofer, M.: Past and future sealevel change from the surface mass balance of glaciers, The Cryosphere, 6, 1295-1322, doi:10.5194/tc-6-1295-2012, 2012.

Meehl, G. A. and Stocker, T. F.: Global climate projections, in: Climate Change 2007: The Physical Science Basis, Contribution of Working Group I to the Fourth Assessment Report of the Intergovernmental Panel on Climate Change, edited by: Solomon, S., Qin, D., Manning, M., Marquis, M., Averyt, K., Tignor, M. M. B., Miller Jr., H. L., and Chen, Z., Cambridge University Press, Cambridge, 2007.

Meier, M. F., Dyurgerov, M. B., Rick, U. K., O’Neel, S., Pfeffer, W. T., Anderson, R. S., Anderson, S. P., and Glazovsky, A. F.: Glaciers dominate eustatic sea-level rise in the 21 st century, Science, 317, 1064-1067, 2007.

Oerlemans, J., Anderson, B., Hubbard, A., Hybrechts, P., Jóhannesson, T., Knap, W. H., Schmeits, M., Stroeven, A. P., van de Wal, R. S. W., Wallinga, J., and Zuo, Z.: Modelling the response of glaciers to climate warming, Clim. Dynam., 14, 267-274, 1998.

Pelto, M. S.: Forecasting temperate alpine glacier survival from accumulation zone observations, The Cryosphere, 4, 67-75, doi:10.5194/tc-4-67-2010, 2010.

Rabatel, A., Letréguilly, A., Dedieu, J.-P., and Eckert, N.: Changes in glacier Equilibrium-Line Altitude (ELA) in the western Alps over the 1984-2010 period: evaluation by remote sensing and modeling of the morpho-topographic and climate controls, The Cryosphere Discuss., 7, 2247-2291, doi:10.5194/tcd-7-22472013, 2013.
Radić, V. and Hock, R.: Regionally differentiated contribution of mountain glaciers and ice caps to future sea-level rise, Nat. Geosci., 4, 91-94, 2011.

Radić, V., Bliss, A., Breedlow, A. C., Hock, R., Miles, E., and Cogley, J. G.: Regional and global projections of twenty-first century glacier mass changes in response to climate scenarios from global climate models, Clim. Dynam., doi:10.1007/s00382-0131719-7, 2013

Raper, S. C. B. and Braithwaite, R. J.: Low sea level rise projections from mountain glaciers and icecaps under global warming, Nature, 439, 311-313, 2006.

Slangen, A. B. A., Katsman, C. A., van de Wal, R. S. W., Vermeersen, L. L. A., and Riva, R. E. M.: Towards regional projections of twenty-first century sea-level change based on IPCC SRES scenarios, Clim. Dynam., 38, 1191-1209, 2012.

World Glacier Monitoring Service (WGMS): Fluctuations of Glaciers 2005-2010 (Vol. X), edited by: Zemp, M., Frey, H., Gärtner-Roer, I., Nussbaumer, S. U., Hoelzle, M., Paul, F., and Haeberli W., ICSU (WDS) / IUGG (IACS) / UNEP / UNESCO / WMO, Zurich, Switzerland, 336 pp., Publication based on database version: doi:10.5904/wgms-fog-2012-11, 2012. 